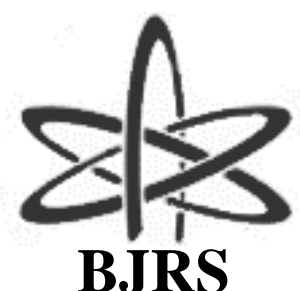

BJRS
BRAZILIAN JOURNAL

$\mathrm{OF}$

RADIATION SCIENCES

08-03B (2021) 01-12

\title{
Probabilistic Safety Analysis and Risk-Based Inspection of nuclear research reactors: state-of-the-art and implementation proposal
}

\author{
Raíssa Oliveira Marques, Vanderley Vasconcelos, Wellington Antonio Soares, \\ Silvério Ferreira Silva Júnior, Amanda Laureano Raso, Amir Zacarias Mesquita \\ Centro de Desenvolvimento da Tecnologia Nuclear - CDTN/CNEN \\ raissaomarques@gmail.com
}

\begin{abstract}
Industrial facilities systems deteriorate over time, thus increasing the possibility of accidents. Risk-Based Inspection (RBI) classifies such systems by their risk information with the purpose of prioritizing inspection efforts. RBI can reduce inspection activities, resulting in lower risk levels, and maintaining reliability and safety in acceptable levels. RiskInformed In-Service Inspection (RI-ISI) is a RBI approach used in nuclear industry. RI-ISI uses outcomes from Probabilistic Safety Analysis (PSA) of Nuclear Power Plants (NPP) to plan In-Service Inspections (ISI). Despite nuclear research reactors are simpler and have lower risks than power reactors, the application of PSA to them may be useful for safety improvements once they are more flexible, provide easier access to its core and allow changes in fuel configurations. Ageing management of components is also required to assure continued adequacy of safety levels, reliable operation, and compliance with operational limits and conditions. This includes periodic review of ISI programs in which monitoring of material deterioration is considered, and that can be supported by the RBI approach. A review of state-of-the-art of PSA and RBI and an implementation proposal applied to nuclear research reactors is presented in this work, as well as its application to a TRIGA reactor using computer codes developed by ReliaSoft ${ }^{\circledR}$ Corporation.
\end{abstract}

Keywords: RBI, PSA, nuclear research reactors. 


\section{INTRODUCTION}

During operation of Nuclear Power Plants (NPPs), equipment deteriorates over time, thus increasing the possibility of accidents. Considering risk as a combination of probability of components or systems failures and the associated consequences, a level of risk should be defined in order to assure safety. Thus, monitoring equipment degradation by inspections is necessary to find out if the risk levels have not been exceeded [1].

Risk-Based Inspection (RBI) is a methodology that classifies systems by their risk information, prioritizing inspection efforts based on this classification. RBI is a probabilistic technique, in which inspection modes and frequencies can be variable, in contrast with deterministic approaches, in which such parameters are constant. This allows RBI to focus on high-risk equipment, reducing inspection activities, without overlooking acceptable safety levels.

Risk-Informed In-Service Inspection (RI-ISI) is a RBI approach used in nuclear industry. RI-ISI uses outcomes from Probabilistic Safety Analysis (PSA) of NPPs to plan In-Service Inspections (ISI), improving safety, reliability and maintenance, as well as reducing radiation exposure. PSA has proved to be a valuable tool for NPPs, analyzing the probabilities of accidents and their consequences for the facility, workers, public and environment. The use of this approach helps to identify the most safety critical components and systems to optimize inspection plans and to detect potential degradation before the operation could be threatened.

Despite nuclear research reactors are simpler than nuclear power plants and have lower risks, the application of PSA and RBI to them may be also useful for safety improvements, because they require more flexibility in operation due to experimental tests, provide easier access to the core and allow changes in fuel configurations. In addition, most of these reactors have long operating histories and can undergo ageing effects [2].

A review of state-of-the-art of PSA and RBI applications to nuclear reactors is presented in this work. Advantages to apply these methodologies to reactors under design, construction, or in operation are also analyzed. PSA and RBI implementation proposal applied to nuclear research reactors is presented, as well as its application to a TRIGA reactor, with support of computer codes developed by ReliaSoft ${ }^{\circledR}$ Corporation. 


\section{PSA IN NUCLEAR POWER PLANTS AND RESEARCH REACTORS}

\subsection{PSA in Nuclear Power Plants}

PSA is a method used to quantify facility risks. It can be applied during the design of NPPs to establish safety requirements. During the facility lifetime, it is used to investigate plant vulnerabilities and to plan inspections, maintenance and repairs, in order to meet technical specifications and to assure performance levels of components and equipment required for safe operation.

The PSA implementation involves the identification of possible accident scenarios, the evaluation of occurrence frequencies of these scenarios, and the modeling of the resulting consequences. These assessments involve uncertainties related mainly to difficulties of identifying all accident scenarios, and the randomness and applicability of available data for estimating the probabilities [3].

PSA is developed with the support of the Event Tree and Fault Tree techniques. Event Trees are used to model possible scenarios of accidents and then evaluate their consequences. An Event Tree starts with the initiating event and progresses through a series of successes or failures of intermediate events (defence-in-depth levels), until an end-state is reached. These defence-in-depth events are used to compensate for potential human and mechanical failures, centred on several levels of protection including successive barriers preventing the release of radioactive material to the environment [4]. Then, Fault Trees is used to estimate the probability of intermediate events of Event Trees, called top events. It depicts the logical interrelationships of basic events that lead to the top event, usually component failures, software errors, or human errors [5].

\subsection{PSA in Research Reactors}

Probabilistic Safety Analysis is a tool used to improve the safety and reliability of power reactors, but may also be applied advantageously to research reactors, particularly those with long operating histories and therefore subject to ageing [6].

Compared to nuclear power plants, research reactors are simpler, as well as the energy generated and radioactive material inventory are much smaller. Therefore, the probability of accidents and 
their consequences are also smaller, leading to lower risks. Because they are simpler and have fewer systems and components, the risk analysis of these reactors is simpler than NPPs. However, as they require greater flexibility in operation due to experimental requirements, it is important the evaluation of potential accidents and the application of PSA tools to nuclear research reactors.

\section{RBI IN NUCLEAR POWER PLANTS AND RESEARCH REACTORS}

\subsection{RBI in Nuclear Power Plants}

Risk Based Inspection (RBI) is a method that optimizes the planning of inspections, based on risk information. In the nuclear area, this method is called Risk-Informed In-Service Inspection (RI-ISI). In-service inspection is a planned activity involving examination, testing and non-destructive evaluation to verify and assure the structural and functional integrity of systems, structures and components of a nuclear reactor [7]. Material degradation information, failure probabilities and their consequences can be estimated from ISI approach. Risk analysis can be carried out using PSA results, which are used to optimize inspection plans, and prioritize high components and locations.

The main advantages of applying RI-ISI to NPPs are: resources are allocated where the risk can most be reduced; fewer inspections are focused on locations to be subjected to a specific degradation mechanism or associated with high risks; and worker radiation exposure can be reduced in accordance with the ALARA (As Low As Reasonably Achievable) principle [8].

\subsection{RBI in Research Reactors}

Despite the growing use of RI-ISI in NPPs around the world, specific results from RBI applied to nuclear research reactors are not easily found in the literature. However, several guides and reports present guidelines for conducting PSA and inspections in these reactors. Thus, it is possible to use this information as a way to improve the planning of inspections, by applying the RBI concept.

Most of research reactors have been in operation for over thirty years. During their lifetime, structures, systems and components are subjected to environmental and operating conditions, such as 
stress, temperature and irradiation, which may lead to changes in the properties of materials [9]. With the purpose of ensuring continued adequacy of safety level, ISI programs should be implemented in order to monitor the materials deterioration.

The planning of inspections involves the definition of the locations and frequencies of the inspections, in addition to the techniques used. In order to define locations and frequencies, the failure probabilities of equipment and components, as well as their relative importance for the safety of the facility, should be considered, prioritizing the locations with greater risks.

Many methods and techniques may be used in inspection programs of nuclear research reactors. They range from methods of dimensional and electrical measurements and chemical analysis to methods of non-destructive examination of the surfaces and volume of structures. The main techniques used are visual inspection, liquid penetrant, magnetic particle, eddy current, radiography and ultrasound [10].

\section{IMPLEMENTATION PROPOSAL OF PSA AND RBI TO RESEARCH REACTORS}

Figure 1 gives an overview of a PSA and RBI implementation proposal for nuclear research reactors. The proposed approach involves the development of a qualitative risk assessment, which results will be used for planning the inspections.

Figure 1: PSA and RBI implementation proposal for nuclear research reactors

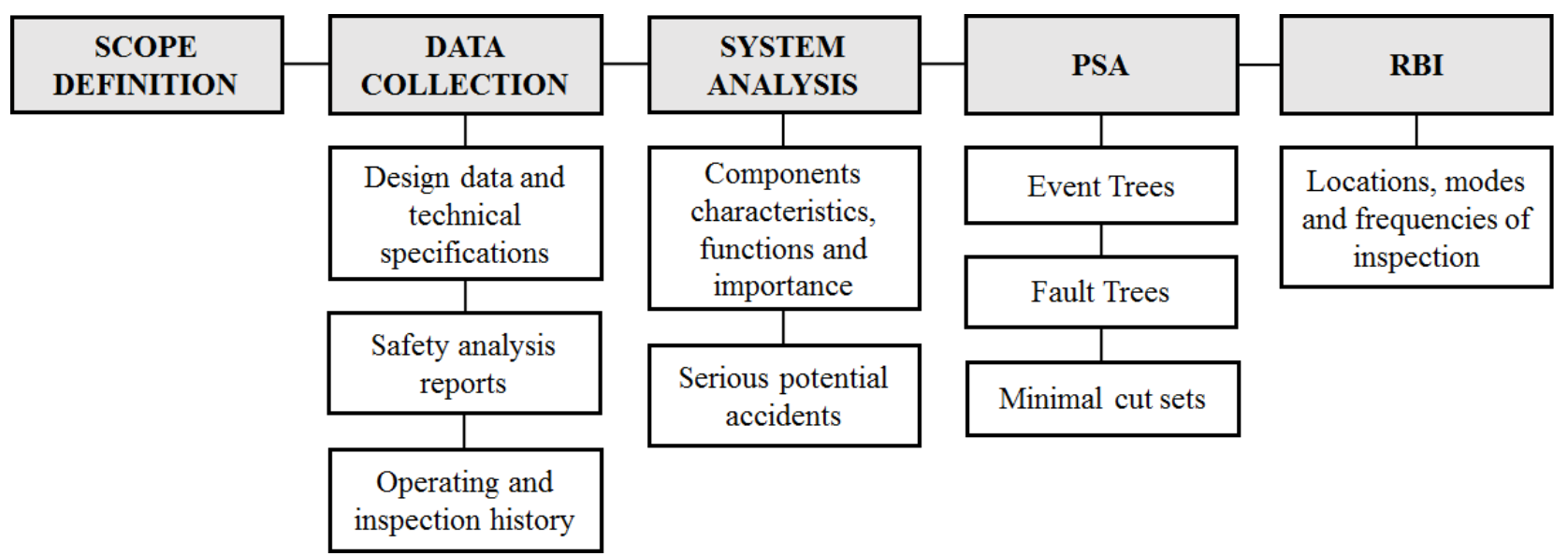


The analysis starts defining the application scope and selecting systems of interest and the corresponding data, which will support the risk assessment. System characteristics are identified from design data, technical specifications and safety analysis reports, and functions and importance of its components for the facility safety are analyzed. It is then possible to identify the most serious potential accidents to be assessed in the PSA approach.

Modeling the accident scenarios is carried out using Event Trees and Fault Trees. A minimal cut set (MCS) of a Fault Tree is the smallest combination of basic events that result in the top event, allowing the evaluation of the most safety critical events.

An inspection plan should take into account both the risk analysis (RBI) performed and the operating and inspection history of the facility. The inspection program includes the definition of locations, modes and frequencies of inspection, in order to ensure safety and reliability.

The proposed method should be implemented with support of risk analysis and reliability computer codes. RENO software for Event Tree Analysis and BLOCKSIM for Fault Tree Analysis, developed by ReliaSoft ${ }^{\circledR}$ Corporation, were used in this work.

\section{TRIGA RESEARCH REACTOR: A CASE STUDY}

The application of the PSA and RBI techniques to a generic TRIGA reactor was the case study used to illustrate the use of the proposed method.

One of the potential accidents in TRIGA reactors is the loss of cooling water from the reactor pool. Figure 2 presents an Event Tree for this initiating event, from which six event sequences (numbered from 1 to 6) are developed, which may affect the safety of the reactor due to failure (F) or success (S) considering the designed defence-in-depth mechanisms. The first protection action is the loss of electrical power, which leads to reactor shutdown, thus being a fail-safe event. On the other hand, if electrical power is available, the following actions will be taken successively to mitigate the consequences: automatic shutdown of the primary circuit pump; automatic shutdown of the cooling system; manual shutdown of the reactor initiated from pool water level information; and manual shutdown of the reactor initiated from radiation information in the pool or reactor area. The failure of all 
these events (sequence 5) leads to the worst case, with the possibility of total loss of pool water. In addition to the rather remote probability of the occurrence of this sequence, it does not cause any loss of integrity of the fuel element cladding. The operating personnel would be exposed to very low radiation doses and there would be no radiological consequence to the public. This analysis is based on two basic assumptions: the TRIGA prompt negative temperature coefficient and the natural convective flow of air through the core [11].

Figure 2: Event Tree for the initiating event "Loss of cooling water from the reactor pool"

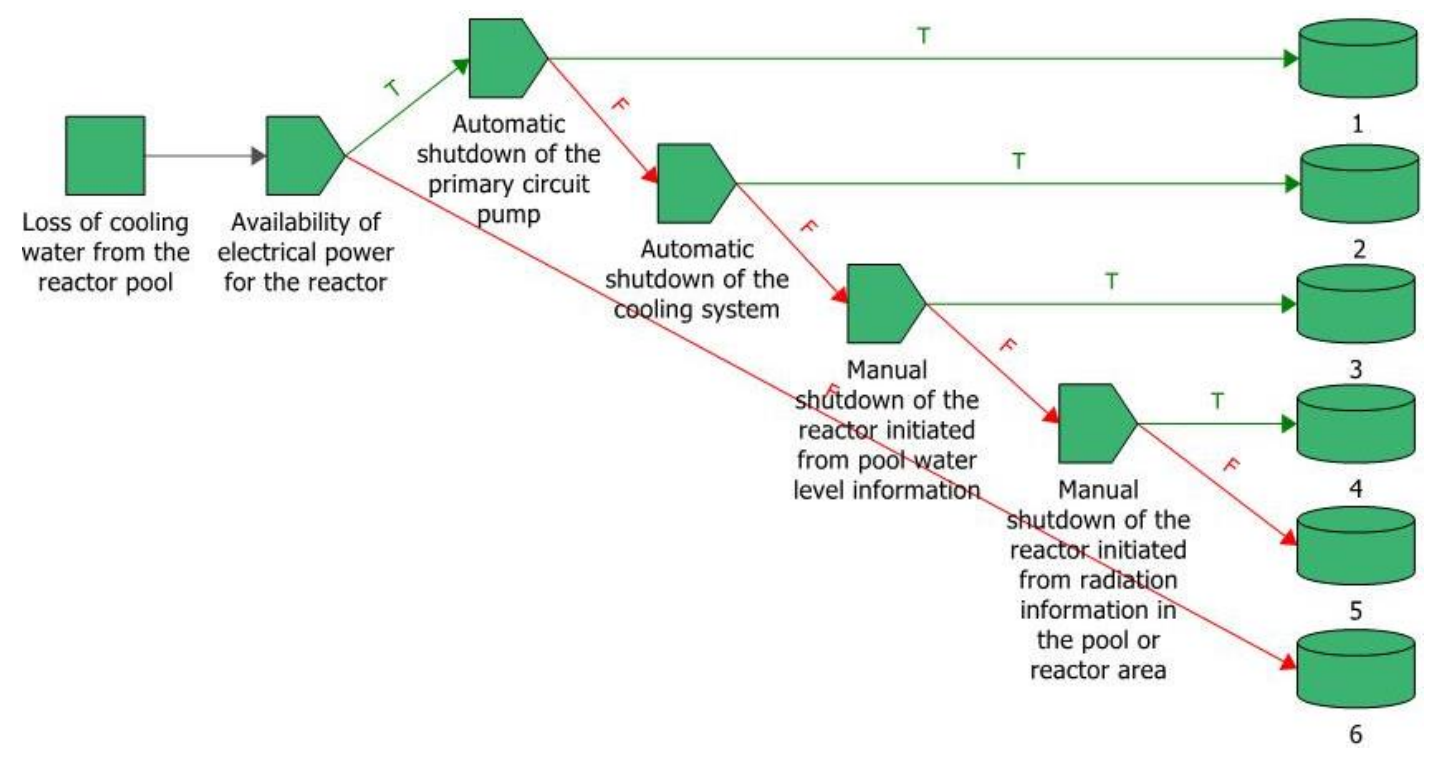

Fault Trees can be used to describe the occurrence of events in accidental sequences of an Event Tree. Some examples are shown in Figures 3, 4 and 5.

Figure 3: Fault Tree for the top event "Failure of automatic shutdown of the cooling system"

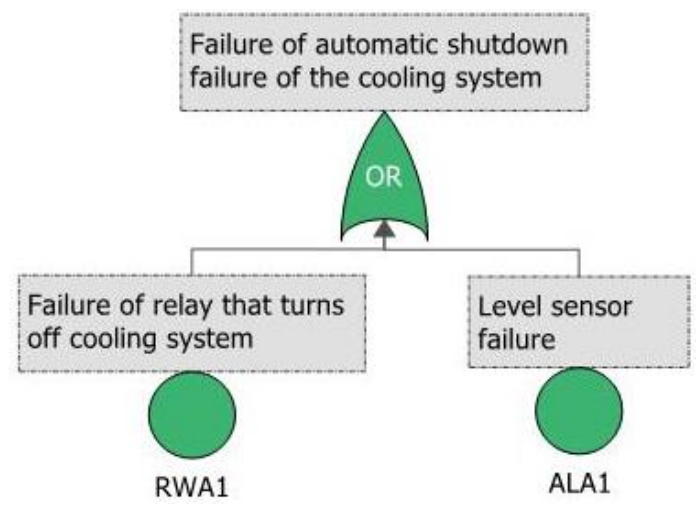


Figure 4: Fault Tree for the top event "Loss of cooling water from the reactor pool"

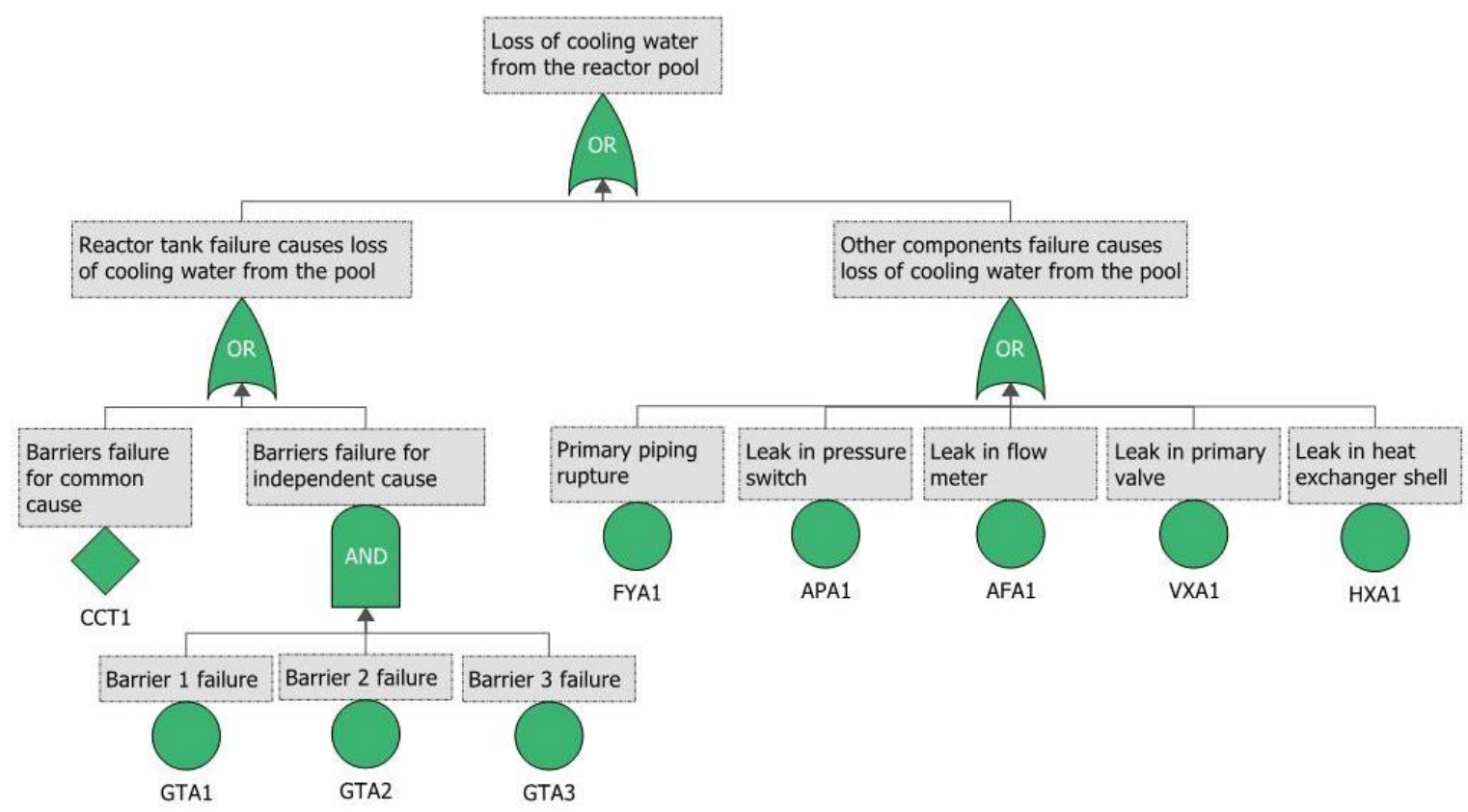

Figure 5: Fault Tree for the top event "Failure of manual shutdown of the reactor initiated from pool water level information"

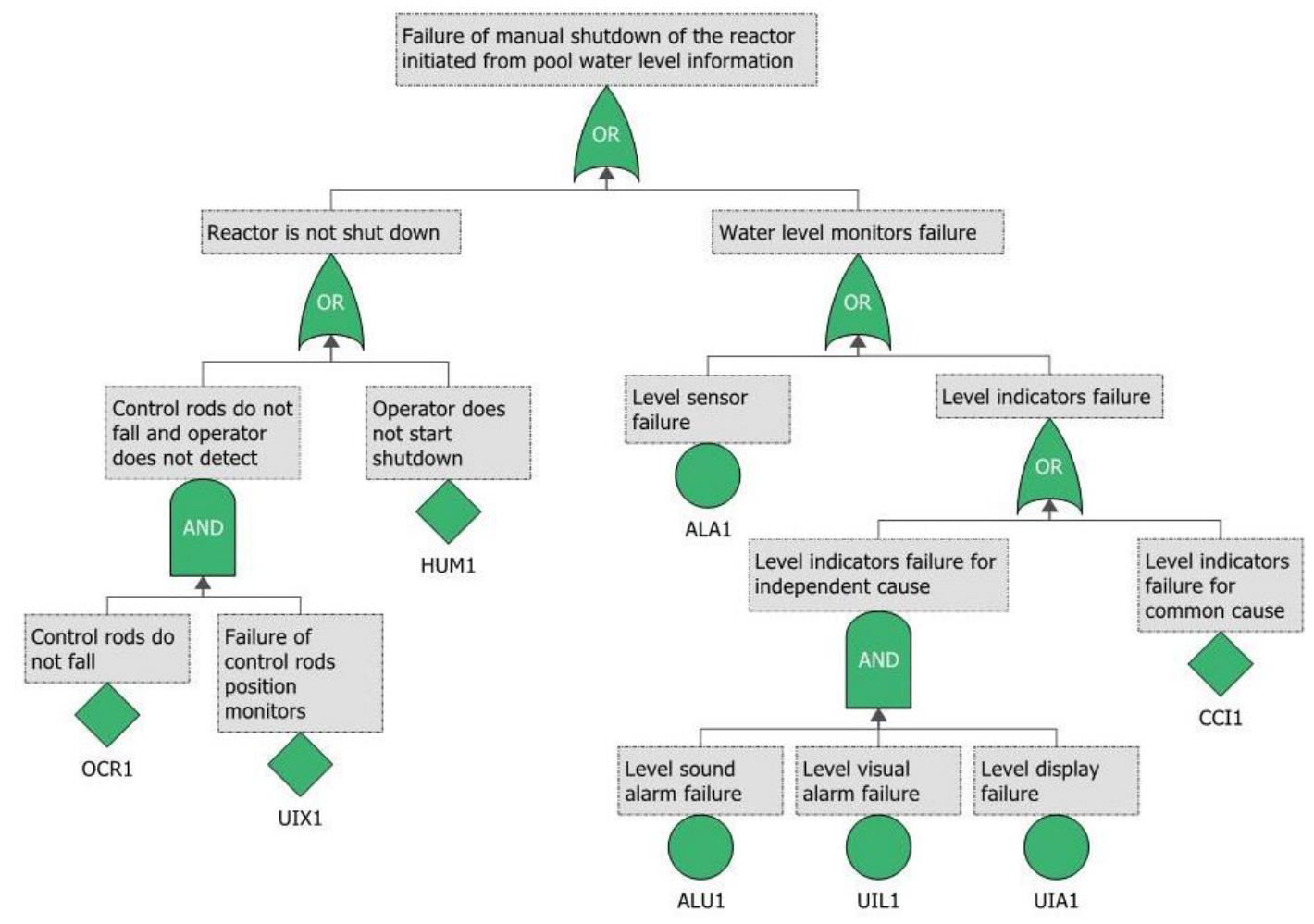


Table 1 shows the minimum cut sets of first order for the Fault Trees in Figures 3, 4 and 5.

Table 1: Minimum cut sets of first order for the Fault Trees in Figures 3, 4 and 5

\begin{tabular}{cc}
\hline Fault Trees & $\begin{array}{c}\text { Minimal Cut Sets of First Or- } \\
\text { der }\end{array}$ \\
\hline Failure of automatic shutdown of the cooling system & ALA1, RWA1 \\
Loss of cooling water from the reactor pool & CCT1, FYA1, APA1, AFA1, \\
$\begin{array}{c}\text { Failure of manual shutdown of the reactor initiated form } \\
\text { the pool water level information }\end{array}$ & ALA1, CCI1, HUM1 \\
\hline
\end{tabular}

Minimal cut sets allow the identification of the most critical components for the facility safety, where inspection efforts should be focused. Table 2 illustrates an inspection schedule for a typical inspection program for research reactors [12] and an inspection-planning proposal, based on RBI analysis, considering the minimum cut sets of first order from Table 1.

The proposed planning includes new inspection techniques (ultrasonic testing, radiography and leak testing) and suggests some changes in the frequency of inspections, considering the locations of greater risks identified in the analysis of minimum cuts sets of first order. For some item like the reactor tank and primary piping, new inspection techniques such as ultrasonic testing and radiography are proposed. For other items, such as the relay of cooling system and level sensor, an increase in inspection frequencies is suggested. A reduction in the inspection frequency could be suggested for the control rods, based only in the qualitative analysis using minimal cut sets, once a single failure does not cause a failure in the reactor scram. However, this was not considered because impact of costs on the reduction of frequency of visual inspection would be negligible. Moreover, in this work only a qualitative risk assessment was carried out. After a more detailed quantitative risk assessment, reduction of inspection frequencies could be justified. 
Table 2: Inspection planning based on RBI analysis

\begin{tabular}{|c|c|c|c|c|}
\hline \multirow{2}{*}{ Components } & \multicolumn{2}{|c|}{ Typical Inspection Program [12] } & \multicolumn{2}{|c|}{ Inspection-Planning Proposal } \\
\hline & Methods & Frequency & Methods & Frequency \\
\hline React & Visual inspection & Onc & $\begin{array}{l}\text { Visual inspection } \\
\text { Ultrasonic testing }\end{array}$ & $\begin{array}{c}\text { Once a year } \\
\text { Once every } 10 \\
\text { years }\end{array}$ \\
\hline Primary & Visual inspection & Once a year & $\begin{array}{c}\text { Visual inspection } \\
\text { Radiography }\end{array}$ & $\begin{array}{c}\text { Once a year } \\
\text { Once every } 10 \\
\text { years }\end{array}$ \\
\hline Pressure switch & Visual inspection & Once a year & $\begin{array}{c}\text { Visual inspection } \\
\text { Leak testing }\end{array}$ & $\begin{array}{c}\text { Once a year } \\
\text { Once every } 10 \\
\text { years }\end{array}$ \\
\hline Flow & Visual inspection & Once a year & $\begin{array}{c}\text { Visual inspection } \\
\text { Leak testing }\end{array}$ & $\begin{array}{c}\text { Once a year } \\
\text { Once every } 10 \\
\text { years }\end{array}$ \\
\hline Prim & Visual inspection & Once a year & $\begin{array}{c}\text { Visual inspection } \\
\text { Leak testing }\end{array}$ & $\begin{array}{c}\text { Once a year } \\
\text { Once every } 10 \\
\text { years }\end{array}$ \\
\hline Heat exchanger & Visual inspection & Once a year & $\begin{array}{l}\text { Visual inspection } \\
\text { Ultrasonic testing }\end{array}$ & $\begin{array}{c}\text { Once a year } \\
\text { Once every } 10 \\
\text { years }\end{array}$ \\
\hline $\begin{array}{c}\text { Relay of cooling } \\
\text { system }\end{array}$ & On / off switch & Four times a year & On / off switch & Once a month \\
\hline Level sensor & $\begin{array}{c}\text { Calibration test- } \\
\text { ing }\end{array}$ & Once a year & $\begin{array}{c}\text { Calibration test- } \\
\text { ing }\end{array}$ & Twice a year \\
\hline Level indicator & Visual inspection & Onc & Visual inspection & Four ti \\
\hline Cont & $\begin{array}{l}\text { Test run of the } \\
\text { component } \\
\text { Visual inspection }\end{array}$ & $\begin{array}{l}\text { Once a month } \\
\text { Once a month }\end{array}$ & $\begin{array}{c}\text { Test run of the } \\
\text { component } \\
\text { Visual inspection }\end{array}$ & $\begin{array}{l}\text { Once a month } \\
\text { Once a month }\end{array}$ \\
\hline $\begin{array}{l}\text { Control rods } \\
\text { position moni- } \\
\text { tors }\end{array}$ & $\begin{array}{l}\text { Calibration test- } \\
\text { ing } \\
\text { Visual inspection }\end{array}$ & $\begin{array}{l}\text { Once a year } \\
\text { Once a year }\end{array}$ & $\begin{array}{l}\text { Calibration test- } \\
\text { ing } \\
\text { Visual inspection }\end{array}$ & $\begin{array}{l}\text { Once a year } \\
\text { Once a year }\end{array}$ \\
\hline
\end{tabular}

\section{CONCLUSIONS}

The Probabilistic Safety Analysis (PSA) and Risk-Based Inspection (RBI) are techniques usually applied to nuclear power plants for purpose of improving safety, reliability and availability of these facilities. Despite nuclear research reactors are simpler and have lower risks, the application of 
these techniques to them is also useful mainly for managing ageing of their structures and components.

PSA can help to identify potential human errors and component failures in prioritizing the most critical events and propose control and mitigation measures. Human factors are of primary importance on safety of research reactors, mainly because their operation conditions are flexible, providing easy access to the core, allowing even changes in fuel configurations. The identification of critical human errors allows evaluating, for example, of the need to improve operation procedures and conduct training of operators. PSA allows also identifying the most critical components and systems for safety, optimizing inspection plans (RBI). A review of state-of-the-art of PSA and RBI applications to nuclear reactors is presented, and a methodology for implementing these techniques to research reactors is proposed.

A case study for a generic TRIGA reactor, evaluating an accident of loss of cooling water from the reactor pool, was carried out using computer codes developed by ReliaSoft ${ }^{\circledR}$ Corporation. Changes in inspection schedule of a typical inspection program by using PSA and RBI approaches were proposed.. Quantitative assessments in future works on this same theme are foreseen.

\section{ACKNOWLEDGMENTS}

The authors would like to thank the following institutions, which sponsored this work: Centro de Desenvolvimento de Tecnologia Nuclear/Comissão Nacional de Energia Nuclear (CDTN/CNEN), Financiadora de Estudos e Projetos (Finep), Fundação de Amparo à Pesquisa do Estado de Minas Gerais (Fapemig), and Conselho Nacional de Desenvolvimento Científico e Tecnológico (CNPq).

\section{REFERENCES}

1. SOARES, W. A.; VASCONCELOS, V.; RABELLO, E. G. Risk-Based Inspection in the Context of Nuclear Power Plants, In: INTERNATIONAL NUCLEAR ATLANTIC CONFERENCE, 2015, São Paulo. Annals... São Paulo: Comissão Nacional de Energia Nuclear, 2015. 
2. MLADIN, D.; PRISECARU, I. Aspects of Probabilistic Safety Assessment for Triga Research Reactor. U.P.B. Sci. Bull., series C, v. 76, iss. 1, p. 261-270, 2014.

3. NASA - National Aeronautics and Space Administration. Probabilistic Risk Assessment Procedures Guide for NASA Managers and Practitioners. NASA/SP-2011-3421, Second Edition, Hanover: NASA, 2011. 431 p.

4. IAEA - International Atomic Energy Agency. Basic Safety Principles for Nuclear Power Plants 75-INSAG-3 Rev. 1. INSAG 12, Vienna: IAEA, 1999. 105 p.

5. IAEA - International Atomic Energy Agency. Development and Application of Level 1 Probabilistic Safety Assessment for Nuclear Power Plants. Specific Safety Guide No. SSG-3, Vienna: IAEA, 2010. 215 p.

6. IAEA - International Atomic Energy Agency. Application of Probabilistic Safety Assessment to Research Reactors. IAEA-TECDOC-517, Vienna: IAEA, 1989. 89 p.

7. CNEN - Comissão Nacional de Energia Nuclear. Inspeção em Serviço em Usinas Nucleoelétricas. CNEN NE 1.25, Rio de Janeiro: CNEN, 1996. 8 p.

8. EC - European Commission. Report on the Regulatory Experience of Risk-Informed Inservice Inspection of Nuclear Power Plant Components and Common Views. EUR 21320 EN, Luxembourg: EC, 2004. 90 p.

9. IAEA - International Atomic Energy Agency. Application of Non-Destructive Testing and InService Inspection to Research Reactors. IAEA-TECDOC-1263, Vienna: IAEA, 2001. 52 p.

10. IAEA - International Atomic Energy Agency. Maintenance, Periodic Testing and Inspection of Research Reactors. IAEA Safety Guide No. NS-G-4.2, Vienna: IAEA, 2006. 81 p.

11. GA - General Atomic. Safeguards Summary Report for the New York University TRIGA MARK I Reactor. GA-9864, San Diego: GE, 1970. 150 p.

12. IAEA - International Atomic Energy Agency. Examples of In-Service Inspections and a Typical Maintenance Schedule for a Low-Power Research Reactor. Vienna. 2005. Available at: <https://ansn.iaea.org/Common/documents/Training/TRIGA\%20Reactors\%20(Safety\%20and\%20T echnology)/pdf/chapter4.pdf>. Last accessed: 06 Nov. 2017. 